\title{
Evidence for a Two-Base Mechanism Involving Tyrosine-265 from Arginine-219 Mutants of Alanine Racemase ${ }^{\dagger}$
}

\author{
Shaoxian Sun and Michael D. Toney* \\ Department of Biochemistry, Albert Einstein College of Medicine, 1300 Morris Park Avenue, Bronx, New York 10461
}

Received December 11, 1998

\begin{abstract}
A positively charged residue, $\mathrm{R} 219$, was found to interact with the pyridine nitrogen of pyridoxal phosphate in the structure of alanine racemase from Bacillus stearothermophilus [Shaw et al. (1997) Biochemistry 36, 1329-1342]. Three site-directed mutants, R219K, R219A, and R219E, have been characterized and compared to the wild type enzyme (WT) to investigate the role of R219 in catalysis. The R219K mutation is functionally conservative, retaining $\sim 25 \%$ of the WT activity. The R219A and R219E mutations decrease enzyme activity by approximately 100- and 1000-fold, respectively. These results demonstrate that a positively charged residue at this position is required for efficient catalysis. R219 and Y265 are connected through H166 via hydrogen bonds. The R219 mutants exhibit similar kinetic isotope effect trends: increased primary isotope effects (1.5-2-fold) but unchanged solvent isotope effects in the $\mathrm{L} \rightarrow \mathrm{D}$ direction and increased solvent isotope effects (1.5-2-fold) but unchanged primary isotope effects in the $\mathrm{D} \rightarrow \mathrm{L}$ direction. These results support a two-base racemization mechanism involving Y265 and K39. They additionally suggest that Y265 is selectively perturbed by R219 mutations through the H166 hydrogen-bond network. $\mathrm{pH}$ profiles show a large $\mathrm{p} K_{\mathrm{a}}$ shift from 7.1-7.4 (WT and $\mathrm{R} 219 \mathrm{~K}$ ) to 9.5-10.4 (R219A and R219E) for $k_{\text {cat }} / K_{\mathrm{M}}$, and from 7.3 to $9.9-10.4$ for $k_{\text {cat }}$ The group responsible for this ionization is likely to be the phenolic hydroxyl of $\mathrm{Y} 265$, whose $\mathrm{p} K_{\mathrm{a}}$ is electrostatically perturbed in the WT by the H166-mediated interaction with R219. Accumulation of an absorbance band at $510 \mathrm{~nm}$, indicative of a quinonoid intermediate, only in the $\mathrm{D} \rightarrow \mathrm{L}$ direction with $\mathrm{R} 219 \mathrm{E}$ provides additional evidence for a two-base mechanism involving Y265.
\end{abstract}

Alanine racemase is an important enzyme in the synthesis of bacterial cell walls (1). It catalyzes the interconversion of L- and D-alanine using pyridoxal phosphate (PLP) ${ }^{1}$ as the cofactor (2). The enzyme is an attractive antibiotic target because it is unique to bacteria and critical for their growth. Studies on alanine racemase have been focused mainly on enzyme inhibition, and a number of potent inhibitors have been characterized $(3-6)$. However, none of the inhibitors has been successful in clinical application, likely due to nonspecific inhibition of PLP enzymes in vivo. It is hoped that a thorough understanding of the mechanism of alanine racemase will aid in the design of mechanism-based inhibitors.

The structure of the catalytic domain of alanine racemase from Bacillus stearothermophilus is that of an $\alpha / \beta$ barrel (7). A similar fold has been proposed for eukaryotic ornithine decarboxylase (8), although the chemical reactions they catalyze are quite different.

The pyridine nitrogen-protonated form of pyridoxal phosphate is generally thought to be required, by acting as an

\footnotetext{
† Supported by Grant NIGMS 54779.

* Corresponding author: Tel 718-430-2347; Fax 718-430-8565; Email toney@aecom.yu.edu.

${ }^{1}$ Abbreviations: PLP, pyridoxal phosphate; TEA-HCl, triethanolamine hydrochloride; CHES, 2-( $N$-cyclohexylamino)ethanesulfonic acid; CAPS, 3-(cyclohexylamino)-1-propanesulfonic acid; KIE, kinetic isotope effect; WT, wild-type enzyme.
}

electron sink, for stabilization of carbanions formed on substrates (Scheme 1). A large number of pyridoxal phosphatedependent enzymes, such as aminotransferases, have a wellconserved, acidic residue likely capable of fully transferring a proton to the coenzyme $(9-11)$. On the other hand, the tryptophan synthase family has a neutral, polar residue (Ser/ Thr) at the corresponding position (12). The active-site structure of alanine racemase shows an unusual interaction between the positively charged guanidino group of R219 and the pyridine nitrogen of PLP. The mechanistic significance of this unusual interaction is explored here by analysis of the R219K, R219A, and R219E mutants.

The active-site structure also shows that H166 mediates an interaction between R219 and Y265. This latter residue has been proposed to be a general acid/base catalyst, along with K39, in a two-base racemization mechanism (7). Kinetic evidence including isotope effects and $\mathrm{pH}$ profiles are presented in support of this proposal and against that of a one-base mechanism.

\section{EXPERIMENTAL PROCEDURES}

Materials. L-Alanine, D-alanine, PLP, CHES, CAPS, and potassium phosphate were obtained from Sigma. NADH and $\mathrm{NAD}^{+}$were from Boehringer Mannheim. D,L- $\left[2-{ }^{2} \mathrm{H}\right]$ Alanine and $\mathrm{L}-\left[2-{ }^{2} \mathrm{H}\right]$ alanine were from Isotech Inc. 
Scheme 1: Mechanism of Alanine Racemization ${ }^{a}$

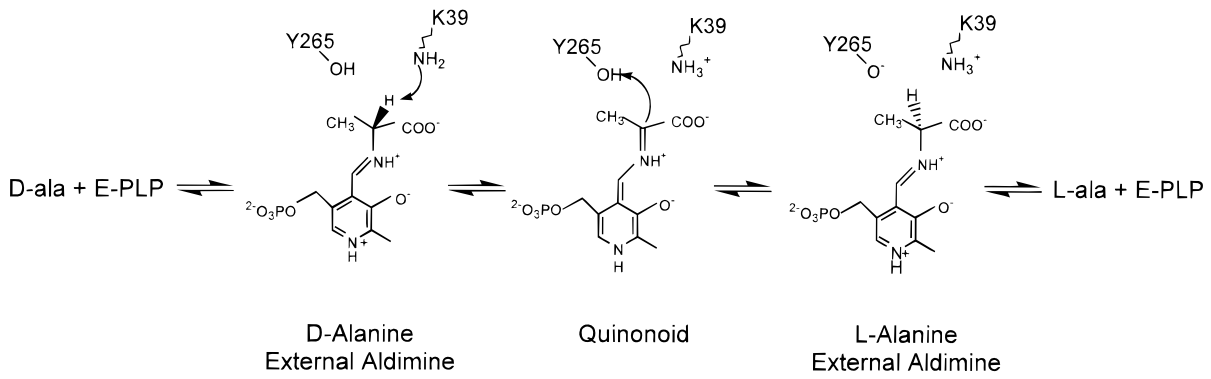

${ }^{a} \mathrm{~K} 39$ forms an imine linkage with PLP in the free enzyme. D- or L-alanine reacts via transimination to give an external aldimine intermediate. The $\alpha$-proton of the substrate is abstracted by an enzymic base, proposed to be either K39 or Y265, to give the quinonoid intermediate. An enzymic acid donates a proton from the opposite side to give the antipodal aldimine. Transimination gives product and regenerates E-PLP.

Alanine dehydrogenase in 50\% glycerol stock solution and pig heart lactate dehydrogenase as an ammonium sulfate precipitate were from Sigma. Pig kidney D-amino acid oxidase as an ammonium sulfate precipitate was purchased from Boehringer Mannheim. Suspensions of lactate dehydrogenase and D-amino acid oxidase were pelleted by centrifugation and dissolved in water before use.

D- $\left[2-{ }^{2} \mathrm{H}\right]$ Alanine was purified from the D,L- $\left[2-{ }^{2} \mathrm{H}\right]$ alanine mixture using a chirobiotic $\mathrm{T}$ chiral column $(250 \times 10.0$ mm, Advanced Separation Technologies Inc.) on a HewlettPackard 1100 HPLC. The conditions were 70\% methanol isocratic elution, flow rate $=1 \mathrm{~mL} / \mathrm{min}$, UV detection at $215 \mathrm{~nm}$. Fractions were assayed using alanine dehydrogenase for $\mathrm{L}-\left[2-{ }^{2} \mathrm{H}\right] \mathrm{alanine}$, and using D-amino acid oxidase coupled to lactate dehydrogenase for $\mathrm{D}-\left[2{ }^{2} \mathrm{H}\right]$ alanine. Fractions of D- $\left[2-{ }^{2} \mathrm{H}\right]$ alanine were pooled and lyophilized.

Gene Cloning. Bacillus stearothermophilus (ATCC 7953) was grown in $100 \mathrm{~mL}$ of a medium containing yeast extract $(0.3 \mathrm{~g})$ and tryptone $(0.5 \mathrm{~g})$ at $55^{\circ} \mathrm{C}$ and harvested after 12 h. Genomic DNA was isolated as described by Saito and Miura (13). Alanine racemase was cloned by PCR based on the gene sequence published by Tanizawa et al. (14). NdeI and BamHI restriction sites were introduced at the $5^{\prime}$ and $3^{\prime}$ ends, respectively, of the alanine racemase gene. The NdeI/ Bam HI double-digested PCR fragment was inserted into similarly digested pET-23a. Alanine racemase was overexpressed in Escherichia coli strain BL21 (DE3) and purified by a modification of the procedure of Inagaki et al. (15), as described below.

Site-Directed Mutagenesis. Site-directed mutagenesis on R219 was performed by overlap extension PCR (16). The mutagenetic oligonucleotides were ACGTTCAATATGGTCXXXTTCGGCATTGCCA (XXX = GCC for alanine, AAA for lysine, or GAA for glutamate), and its complement. Mutant clones were fully sequenced to ensure that no mutations occurred except at the desired position.

Enzyme Purification. The plasmid for WT or mutant was transformed into $E$. coli BL21 (DE3). The cells were grown in LB at $37{ }^{\circ} \mathrm{C}$ to $A_{600} \sim 1.0$ and induced with $0.2 \mathrm{mM}$ IPTG. Cells were harvested after $3 \mathrm{~h}$ and resuspended in $30 \mathrm{mM}$ TEA-HCl at $\mathrm{pH} 8.0,100 \mathrm{mM}$ sodium acetate, $20 \mu \mathrm{M}$ PLP, and $0.1 \% \beta$-mercaptoethanol. They were lysed by incubation with $0.5 \mathrm{mg} / \mathrm{mL}$ lysozyme at $37^{\circ} \mathrm{C}$ for $30 \mathrm{~min}$, followed by sonication. The supernatant was kept at $70{ }^{\circ} \mathrm{C}$ for $1 \mathrm{~h}$ for the WT enzyme and at $55^{\circ} \mathrm{C}$ for $30 \mathrm{~min}$ for the mutants. After the heat shock, the supernatant was loaded onto a 100
$\mathrm{mL}$ Fast $\mathrm{Q}$ anion-exchange column (Pharmacia) equilibrated with $100 \mathrm{mM}$ sodium acetate, $30 \mathrm{mM}$ TEA-HCl, $\mathrm{pH}$ 8.0, 20 $\mu \mathrm{M}$ PLP, and $0.1 \% \beta$-mercaptoethanol. Protein was eluted with a $400 \mathrm{~mL}$ gradient of $100-400 \mathrm{mM}$ sodium acetate, $30 \mathrm{mM}$ TEA-HCl, $\mathrm{pH}$ 8.0, $20 \mu \mathrm{M}$ PLP, and $0.1 \% \beta$-mercaptoethanol. Fractions were assayed for activity and by SDS-PAGE. The fractions containing pure alanine racemase were pooled, concentrated, and flash-frozen in 2-propanol/ dry ice. The enzyme was stored at $-70{ }^{\circ} \mathrm{C}$. Protein concentration was determined by the DC protein assay (modified Lowry) from Bio-Rad with bovine serum albumin as the standard.

Enzyme Activity Assay. For the $\mathrm{D} \rightarrow \mathrm{L}$ direction, the reaction was followed by the formation of NADH at 340 $\mathrm{nm}$ in a coupled reaction with L-alanine dehydrogenase. For the $\mathrm{L} \rightarrow \mathrm{D}$ direction, D-amino acid oxidase and lactate dehydrogenase were used as the coupling enzymes. The reaction was followed at $340 \mathrm{~nm}$. The extinction coefficient of NADH at $340 \mathrm{~nm}$ was taken to be $6220 \mathrm{M}^{-1} \mathrm{~cm}^{-1}$. All experiments were performed at $25^{\circ} \mathrm{C}$. Reactions for the D $\rightarrow \mathrm{L}$ direction were performed in buffer containing $50 \mu \mathrm{M}$ PLP, $0.1 \mathrm{M} \mathrm{KCl}, 10 \mathrm{mM} \mathrm{NAD}^{+}$, 0.05-20 mM D-alanine, 2 units/mL alanine dehydrogenase, and 0.1 M CHES, pH 9.0, while those for the $\mathrm{L} \rightarrow \mathrm{D}$ direction contained $50 \mu \mathrm{M}$ PLP, $0.1 \mathrm{M} \mathrm{KCl}, 0.2 \mathrm{mM} \mathrm{NADH}, 0.1-40 \mathrm{mM}$ L-alanine, 1.5 units/ $\mathrm{mL}$ D-amino acid oxidase, 51 units $/ \mathrm{mL}$ lactate dehydrogenase, and 0.1 M CHES, $\mathrm{pH}$ 9.0. The enzyme concentrations were $0.11 \mathrm{nM}$ for WT, $0.48 \mathrm{nM}$ for R219K, $68 \mathrm{nM}$ for $\mathrm{R} 219 \mathrm{~A}$, and $255 \mathrm{nM}$ for R219E.

Isotope Effects and Proton Inventories. Primary isotope effects were measured under identical reaction conditions as described above by employing D-[2- $\left.{ }^{2} \mathrm{H}\right]$ alanine as the substrate in the $\mathrm{D} \rightarrow \mathrm{L}$ direction and $\mathrm{L}-\left[2{ }^{2} \mathrm{H}\right]$ alanine in $\mathrm{L} \rightarrow$ $\mathrm{D}$ direction. Solvent isotope effects were obtained by conducting the reaction in $\mathrm{D}_{2} \mathrm{O}$ under the same experimental conditions as in $\mathrm{H}_{2} \mathrm{O}$. The $\mathrm{pD}$ of the reaction was adjusted to the appropriate value based on the equation $\mathrm{pD}=\mathrm{pH}+$ 0.5 (17).

In proton inventory studies, appropriate volumes of $\mathrm{H}_{2} \mathrm{O}$ and $\mathrm{D}_{2} \mathrm{O}$ buffers were mixed to give the required atom fraction of deuterium. Reaction solutions were incubated with enzyme solution (prepared in $\mathrm{H}_{2} \mathrm{O}$ ) for 10 min to equilibrate exchangeable protons. They were initiated by addition of substrate solution (prepared in $\mathrm{H}_{2} \mathrm{O}$ ). The value of atom fraction of deuterium, $n$, was corrected for protium introduced from enzyme and substrate solutions. Proton inventories on $k_{\text {cat }}$ were measured with saturating substrate concentrations 
Table 1: Kinetic Parameters of Wild Type and R219 Mutants of Alanine Racemase ${ }^{a}$

\begin{tabular}{llccc}
\hline & \multicolumn{2}{c}{$\mathrm{D} \rightarrow \mathrm{L}^{b}$} & \multicolumn{2}{c}{$\mathrm{L} \rightarrow \mathrm{D}^{c}$} \\
\cline { 2 - 5 } & \multicolumn{1}{c}{$k_{\mathrm{cat}}\left(\mathrm{s}^{-1}\right)$} & $k_{\mathrm{cat}} / K_{\mathrm{M}}\left(\mathrm{M}^{-1} \mathrm{~s}^{-1}\right)$ & $1.4(0.02) \times 10^{3}$ & $k_{\mathrm{cat}} / K_{\mathrm{M}}\left(\mathrm{M}^{-1} \mathrm{~s}^{-1}\right)$ \\
\hline wild type & $1.1(0.02) \times 10^{3}$ & $4.0(0.3) \times 10^{5}$ & $4.7(0.3) \times 10^{5}$ \\
R219K & $3.5(0.2) \times 10^{2}$ & $9.5(0.5) \times 10^{4}$ & $7.5(0.2) \times 10^{2}$ & $9.5(0.3) \times 10^{4}$ \\
R219A & $0.97(0.01)$ & $3.2(0.1) \times 10^{3}$ & $1.3(0.01)$ & $3.7(0.2) \times 10^{3}$ \\
R219E & $0.32(0.01)$ & $6.0(0.2) \times 10^{2}$ & $0.42(0.02)$ & $7.7(0.3) \times 10^{2}$ \\
\hline
\end{tabular}

${ }^{a}$ Errors are given in parentheses. Enzyme concentrations used: WT, $0.11 \mathrm{nM}$; R219A, $68 \mathrm{nM}$; R219E, $255 \mathrm{nM}$; R219K, $0.48 \mathrm{nM} .{ }^{b}$ Conversion of $\mathrm{D}$ to L-alanine was followed by coupling to L-alanine dehydrogenase. Conditions: $0.1 \mathrm{M} \mathrm{CHES,} \mathrm{pH} \mathrm{9.0,50} \mu \mathrm{M} \mathrm{PLP}, 0.1 \mathrm{M} \mathrm{KCl,} 10 \mathrm{mM} \mathrm{NAD}{ }^{+}$, 0.05-20 mM D-alanine, and 2 units $/ \mathrm{mL}$ alanine dehydrogenase, $25{ }^{\circ} \mathrm{C} .{ }^{c}$ Conversion of L- to D-alanine was followed by coupling to D-amino acid

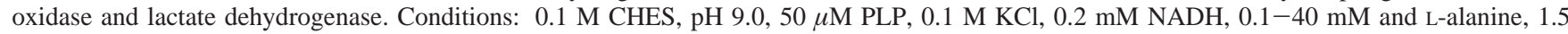
units/mL DAAO, and 51 units/mL LDH, $25^{\circ} \mathrm{C}$.

Table 2: Primary and Solvent Isotope Effects for Wild Type and R219 Mutants of Alanine Racemase ${ }^{a}$

\begin{tabular}{|c|c|c|c|c|c|c|c|c|}
\hline & \multicolumn{4}{|c|}{$\mathrm{D} \rightarrow \mathrm{L}^{b}$} & \multicolumn{4}{|c|}{$\mathrm{L} \rightarrow \mathrm{D}^{c}$} \\
\hline & ${ }^{\mathrm{D}} k_{\text {cat }}$ & ${ }^{\mathrm{D}} k_{\mathrm{cat}} / K_{\mathrm{M}}$ & ${ }^{\mathrm{DOD}} k_{\mathrm{cat}}$ & ${ }^{\mathrm{DOD}} k_{\mathrm{cat}} / K_{\mathrm{M}}$ & ${ }^{\mathrm{D}} k_{\text {cat }}$ & ${ }^{\mathrm{D}} k_{\mathrm{cat}} / K_{\mathrm{M}}$ & ${ }^{\mathrm{DOD}} k_{\mathrm{cat}}$ & ${ }^{\mathrm{DOD}} k_{\mathrm{cat}} / K_{\mathrm{M}}$ \\
\hline wild type & $1.4(0.03)$ & $1.3(0.1)$ & $1.6(0.06)$ & $1.0(0.1)$ & $1.5(0.1)$ & $1.6(0.1)$ & $1.4(0.1)$ & $1.1(0.1)$ \\
\hline R219K & $1.8(0.05)$ & $1.8(0.1)$ & $1.5(0.04)$ & $1.6(0.1)$ & $3.2(0.07)$ & $2.7(0.2)$ & $1.5(0.03)$ & $1.1(0.1)$ \\
\hline R219A & $1.2(0.01)$ & $1.5(0.07)$ & $1.4(0.07)$ & $1.8(0.1)$ & $3.5(0.04)$ & $2.2(0.2)$ & $1.8(0.04)$ & $1.3(0.2)$ \\
\hline R219E & $1.1(0.02)$ & $1.4(0.07)$ & $2.0(0.02)$ & $1.9(0.1)$ & $3.4(0.1)$ & $2.4(0.2)$ & $1.8(0.07)$ & $1.6(0.1)$ \\
\hline
\end{tabular}

${ }^{a}$ Reactions were performed under the experimental conditions described in Table 1 except that $\left[2-{ }^{2} \mathrm{H}\right]-\mathrm{D}$ or $\left[2-{ }^{2} \mathrm{H}\right]-\mathrm{L}-$ alanine was employed as the substrate for primary KIEs and $\mathrm{D}_{2} \mathrm{O}$ was used for solvent KIEs. Errors given in parentheses.

(15 mM D-alanine or $30 \mathrm{mM} \mathrm{L-alanine).}$

pH Profiles. Three buffers were used in the $\mathrm{pH}$ profile studies: $0.1 \mathrm{M}$ potassium phosphate for $\mathrm{pH} 6.5-8.0,0.1 \mathrm{M}$ CHES for $\mathrm{pH}$ 8.3-9.7, and 0.1 M CAPS for $\mathrm{pH} 10-11$. Ionic strength was maintained at $0.2 \mathrm{M}$ with potassium chloride. Reactions were initiated by addition of enzyme solution. The final $\mathrm{pH}$ value was measured after $20 \mathrm{~min}$ of reaction.

Pre-Steady-State Kinetics. Enzyme and substrate solutions were rapidly mixed in an Applied Photophysics SX17.MV stopped-flow spectrophotometer. Coenzyme spectral changes were monitored with a diode-array detector. Absorbance scans from 300 to $500 \mathrm{~nm}$ were collected on a logarithmic time scale over 10-20 s. Data were analyzed by global fitting of the spectra with SPECFIT (Spectrum Software Associates). Reactions were performed in 0.1 M CHES, $\mathrm{pH}$ 9.0, $0.1 \mathrm{M} \mathrm{KCl}, 2-10 \mathrm{mM}$ D- or L-alanine, $16-25 \mu \mathrm{M}$ enzyme, $25^{\circ} \mathrm{C}$.

\section{RESULTS}

Catalytic Activities of R219 Mutants. The kinetic parameters of WT and R219 mutants in the D $\rightarrow$ L and L $\rightarrow$ D reactions are listed in Table 1 . The WT values are close to the data reported by Faraci and Walsh (18). The equilibrium constant $K=\left(k_{\text {cat }} / K_{\mathrm{M}}\right)_{\mathrm{D} \rightarrow \mathrm{L}} /\left(k_{\text {cat }} / K_{\mathrm{M}}\right)_{\mathrm{L} \rightarrow \text { D }}$ is equal to 1 , within error, for the WT and mutant enzymes, as predicted by the Haldane relationship (19). R219K is a functionally conservative mutation; enzyme activity decreases by only $2-5$-fold. Mutation of R219 to either a neutral (R219A) or a negatively charged (R219E) residue reduces enzyme activity by 1001000-fold.

Primary and Solvent Isotope Effects for WT and Mutant Enzymes. Table 2 lists the primary and solvent KIEs on $k_{\text {cat }}$ and $k_{\mathrm{cat}} / K_{\mathrm{M}}$ for WT and mutant enzymes in both directions. For the WT enzyme, the primary KIEs are small but significant. The solvent KIEs are significant for $k_{\text {cat }}$ but are, within error, absent in $k_{\text {cat }} / K_{\mathrm{M}}$. The time course for the WTcatalyzed reaction of protiated L-alanine in $\mathrm{D}_{2} \mathrm{O}$, followed by circular dichroism, showed an overshoot of the equilibrium position followed by an eventual return (data not shown). This "overshoot" is attributed to a primary isotope effect (20).

Compared to the WT enzyme, all three mutants show similar or larger primary and solvent isotope effects in both directions. The most striking differences are the solvent isotope effects on $k_{\text {cat }} / K_{\mathrm{M}}$ in the $\mathrm{D} \rightarrow$ L direction and the primary isotope effects in $\mathrm{L} \rightarrow \mathrm{D}$.

Proton Inventories on $k_{\text {cat }}$ for WT and R219E. Compared to simple solvent KIE measurements, which assess the effect of going from pure $\mathrm{H}_{2} \mathrm{O}$ to pure $\mathrm{D}_{2} \mathrm{O}$, proton inventories provide additional information on the origin of the solvent KIEs. In this method $(17,21)$, the reaction rate is measured as a function of the atom fraction of deuterium in $\mathrm{H}_{2} \mathrm{O} / \mathrm{D}_{2} \mathrm{O}$ mixtures. Proton inventories for WT and R219E in both $\mathrm{D}$ $\rightarrow \mathrm{L}($ Figure $1 \mathrm{~A}$ ) and $\mathrm{L} \rightarrow \mathrm{D}$ (Figure 1B) directions were measured at saturating substrate concentrations, yielding proton inventories on $k_{\text {cat }}$.

The data for WT and R219E were fitted to two different mechanisms:

$$
\begin{gathered}
\frac{k_{n}}{k_{0}}=1-n+\left(\frac{n}{k_{0} / k_{1}}\right) \\
\frac{k_{n}}{k_{0}}=\left(\frac{k_{0}}{k_{1}}\right)^{-n}
\end{gathered}
$$

Here, $n$ is the atom fraction of deuterium and $k_{0} / k_{1}$ is the solvent isotope effect. Equation 1 describes a transition state in which a single proton is transferred and defines a linear curve. Equation 2 describes a transition state in which multiple protons are transferred and defines a "bowl-shaped" curve. Proton inventories for WT fit well to a straight line, eq 1, in both directions. Unlike the WT, the R219E proton inventory in the $\mathrm{D} \rightarrow \mathrm{L}$ direction is nonlinear and is best described by eq 2 (Figure 1A). The R219E data for the $\mathrm{L} \rightarrow$ D direction, like WT, fit best to a straight line (Figure 1B). 

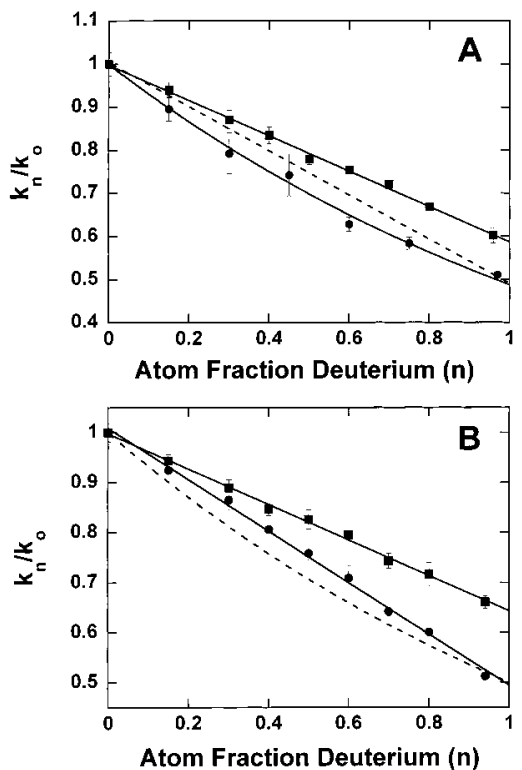

Figure 1: Proton inventories for WT $(\boldsymbol{\square})$ and R219E (O). Data for the $\mathrm{D} \rightarrow \mathrm{L}$ direction are shown in panel A, while those for the $\mathrm{L} \rightarrow \mathrm{D}$ direction are shown in panel B. The data for WT fit best to straight lines, which are shown. The R219E data fit best to a multiproton model in the $\mathrm{D} \rightarrow \mathrm{L}$ direction but to a straight line in the $\mathrm{L} \rightarrow \mathrm{D}$ direction. Dashed lines are for the corresponding oneproton or multiproton fits, given identical solvent KIEs.
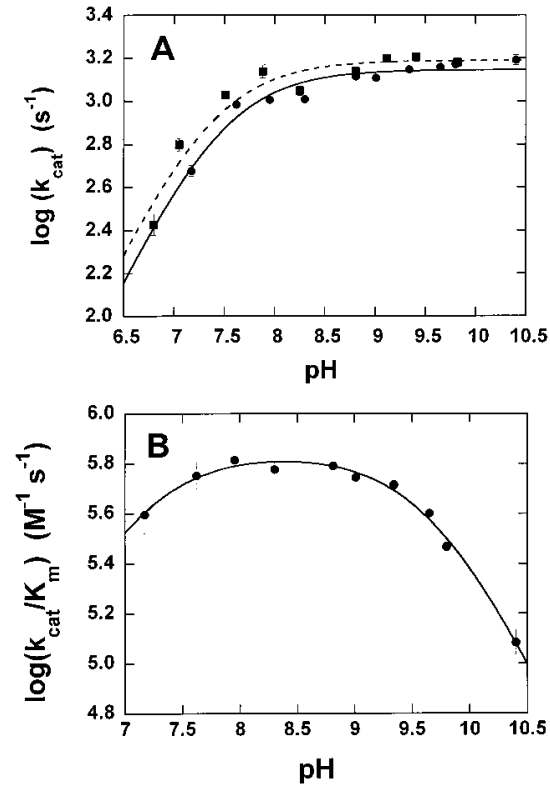

FIGURE 2: pH profiles for WT: (A) $k_{\mathrm{cat}}$, (B) $k_{\mathrm{cat}} / K_{\mathrm{M}}$. (๑) D $\rightarrow \mathrm{L}$ direction; $(\mathbf{\square}), \mathrm{L} \rightarrow \mathrm{D}$ direction. For $k_{\mathrm{cat}}$, curves are the best fits to eq 3 (solid line, $\mathrm{D} \rightarrow \mathrm{L}$; dashed line, $\mathrm{L} \rightarrow \mathrm{D}$ ). For $k_{\text {cat }} / K_{\mathrm{M}}$, the curve is the best fit to eq $4 . \mathrm{p} K_{\mathrm{a}}$ values are given in Table 3 .

pH Profiles for WT and Mutant Enzymes. WT $k_{\text {cat }} \mathrm{pH}$ profiles for both directions are shown in Figure 2A. The data indicate a single ionization and were thus fitted to eq 3 :

$$
k_{\mathrm{cat}}=\frac{k_{\mathrm{A}-} \times 10^{\mathrm{pH}-\mathrm{p} K_{\mathrm{a}}}}{1+10^{\mathrm{pH}-\mathrm{p} K_{\mathrm{a}}}}
$$

The $\mathrm{p} K_{\mathrm{a}}$ values obtained from all of the profiles are collected in Table 3. The $\mathrm{pH}$ profile for $k_{\mathrm{cat}} / K_{\mathrm{M}}$ measured in the $\mathrm{D} \rightarrow$ $\mathrm{L}$ direction is equivalent to that for the $\mathrm{L} \rightarrow \mathrm{D}$ direction since the equilibrium constant is unity. The $k_{\text {cat }} / K_{\mathrm{M}}$ data are shown
Table 3: Summary of the $\mathrm{p} K_{\mathrm{a}}$ Values Obtained from $\mathrm{pH}$ Profiles for Wild Type and R219 Mutants ${ }^{a}$

\begin{tabular}{lcrlcr}
\hline & \multicolumn{2}{c}{$\mathrm{p} K_{\mathrm{a}}(\mathrm{D} \rightarrow \mathrm{L})$} & & \multicolumn{2}{c}{$\mathrm{p} K_{\mathrm{a}}(\mathrm{L} \rightarrow \mathrm{D})$} \\
\cline { 2 - 3 } \cline { 6 - 6 } & \multicolumn{1}{c}{$k_{\text {cat }}$} & $k_{\text {cat }} / K_{\mathrm{M}}$ & & $k_{\text {cat }}$ & $k_{\text {cat }} / K_{\mathrm{M}}{ }^{b}$ \\
\hline wild type & $7.4(0.1)$ & $7.0(0.1)$ & & $7.3(0.1)$ & $7.0(0.1)$ \\
& & $9.7(0.1)$ & & $9.7(0.1)$ \\
$\mathrm{R} 219 \mathrm{~K}$ & $7.3(0.1)$ & $7.1(0.1)$ & & $7.4(0.1)$ & $7.1(0.1)$ \\
& $10.1(0.3)$ & $9.7(0.1)$ & & $9.7(0.1)$ \\
$\mathrm{R}^{2} 19 A^{c}$ & $10.4(0.1)$ & $9.5(0.2)$ & & 10.4 & $9.5(0.2)$ \\
& & $10.5(0.2)$ & & $10.5(0.2)$ \\
$\mathrm{R}^{2} 19 E^{d}$ & $9.9(0.1)$ & $9.6(0.1)$ & & $9.9(0.1)$ & $9.6(0.1)$ \\
\hline
\end{tabular}

${ }^{a}$ Errors are given in parentheses. ${ }^{b}$ The $\mathrm{p} K_{\mathrm{a}}$ for $k_{\mathrm{cat}} / K_{\mathrm{M}}$ in $\mathrm{L} \rightarrow \mathrm{D}$ are equivalent to those measured in the $\mathrm{D} \rightarrow \mathrm{L}$ direction since the equilibrium constant is unity. The values given are those measured for the $\mathrm{D} \rightarrow$ L direction. ${ }^{c}$ The $\mathrm{p} K_{\mathrm{a}}$ in the $\mathrm{L} \rightarrow \mathrm{D}$ direction on $k_{\text {cat }}$ is an approximate value. Reaction rates in the $\mathrm{L} \rightarrow \mathrm{D}$ direction were measured in a $\mathrm{pH}$ range of $7-10$, which is insufficient to define this high $\mathrm{p} K_{\mathrm{a}}$ value.
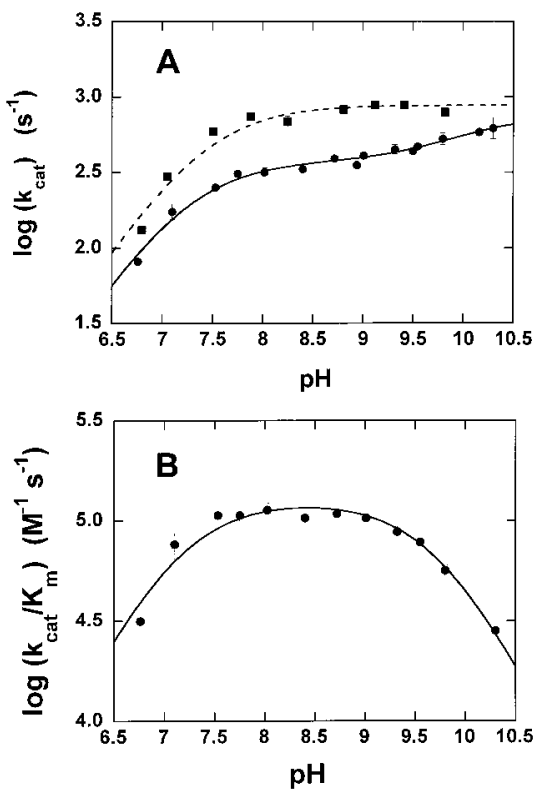

FIGURE 3: pH profiles for R219K: (A) $k_{\text {cat }}$, (B) $k_{\text {cat }} / K_{\mathrm{M}}$. (๑) D $\rightarrow$ $\mathrm{L}$ direction; $(\mathbf{\square}) \mathrm{L} \rightarrow \mathrm{D}$ direction. For $k_{\mathrm{cat}}$, curves are the best fits to eq 5 for $\mathrm{D} \rightarrow \mathrm{L}$ (solid line) and to eq 3 for $\mathrm{L} \rightarrow \mathrm{D}$ (dashed line). For $k_{\text {cat }} / K_{\mathrm{M}}$, the curve is the best fit to eq 4. $\mathrm{p} K_{\mathrm{a}}$ values are given in Table 3.

in Figure 2B. They were fitted to eq 4, which describes a bell-shaped curve:

$$
\frac{k_{\mathrm{cat}}}{K_{\mathrm{M}}}=\frac{k_{\mathrm{HA}}}{1+10^{\mathrm{p} K_{\mathrm{a} 1}-\mathrm{pH}}+10^{\mathrm{pH}-\mathrm{p} K_{\mathrm{a} 2}}}
$$

For $\mathrm{R} 219 \mathrm{~K}, \mathrm{pH}$ profiles for $k_{\text {cat }}$ in both directions are shown in Figure 3A. The data for the $\mathrm{L} \rightarrow \mathrm{D}$ direction were fitted to eq 3 . In the $\mathrm{D} \rightarrow \mathrm{L}$ direction, a second ionization is observed at high $\mathrm{pH}$, thus these data were fitted to eq 5 :

$$
k_{\text {cat }}=\frac{k_{\mathrm{HA}-}+k_{\mathrm{A} 2-} \times 10^{\mathrm{pH}-\mathrm{p} K_{\mathrm{a} 2}}}{1+10^{\mathrm{p} K_{\mathrm{a} 1}-\mathrm{pH}}+10^{\mathrm{pH}-\mathrm{p} K_{\mathrm{a} 2}}}
$$

The $\mathrm{pH}$ profile for $k_{\mathrm{cat}} / K_{\mathrm{M}}$ (Figure $3 \mathrm{~B}$ ) is clearly bell-shaped. The data were thus fitted to eq 4 .

The $k_{\text {cat }} \mathrm{pH}$ profiles for $\mathrm{R} 219 \mathrm{~A}$ and $\mathrm{R} 219 \mathrm{E}$ in both directions are shown in Figures 4A and 5A, respectively. The data do not approach zero at low $\mathrm{pH}$, thus they were 

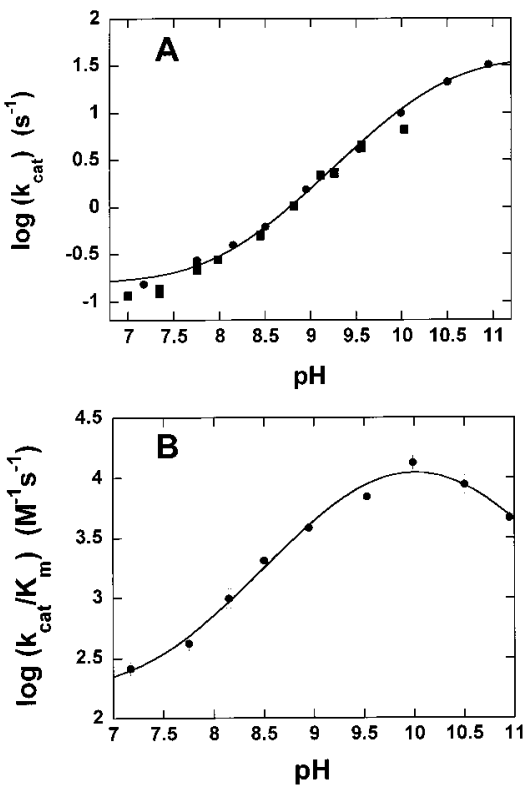

FiguRE 4: pH profiles for R219A: (A) $k_{\text {cat }}$, (B) $k_{\text {cat }} / K_{\mathrm{M}}$. (०) D $\rightarrow$ $\mathrm{L}$ direction; $(\mathbf{\square}) \mathrm{L} \rightarrow \mathrm{D}$ direction. For $k_{\mathrm{cat}}$, the curve is the best fit to eq 6 for $\mathrm{D} \rightarrow \mathrm{L}$ (solid line). For $k_{\text {cat }} / K_{\mathrm{M}}$, the curve is the best fit to eq 7. $\mathrm{p} K_{\mathrm{a}}$ values are given in Table 3 .

fitted to eq 6 :

$$
k_{\mathrm{cat}}=\frac{k_{\mathrm{HA}}+k_{\mathrm{A}-} \times 10^{\mathrm{pH}-\mathrm{p} K_{\mathrm{a}}}}{1+10^{\mathrm{pH}-\mathrm{p} K_{\mathrm{a}}}}
$$

The $\mathrm{pH}$ profiles for $k_{\text {cat }} / K_{\mathrm{M}}$ are shown in Figures $4 \mathrm{~B}$ and 5B. These data also do not approach zero at low $\mathrm{pH}$, requiring the use of eq 7 :

$$
\frac{k_{\mathrm{cat}}}{K_{\mathrm{M}}}=\frac{k_{\mathrm{HA}-}+k_{\mathrm{H} 2 \mathrm{~A}} \times 10^{\mathrm{pK}_{\mathrm{a} 1}-\mathrm{pH}}}{1+10^{\mathrm{pK}_{\mathrm{a} 1}-\mathrm{pH}}+10^{\mathrm{pH}^{\mathrm{p}-\mathrm{pK}_{\mathrm{a} 2}}}}
$$

Quinonoid Intermediate Formation in the $D \rightarrow{ }_{L}$ Reaction for R219E. Coenzyme spectral changes were monitored in the pre-steady-state reaction of $\mathrm{R} 219 \mathrm{E}$ with saturating D-alanine. Analysis of the spectral changes indicates a twoexponential approach to the steady-state. Global fitting of the spectra versus time data to a two-exponential mechanism yielded the spectra for the intermediates shown in Figure 6. Absorbance at $\sim 510 \mathrm{~nm}$ is observed in the spectra of the intermediate and final species, indicating accumulation of a quinonoid intermediate. The rate constants are $k_{\text {fast }}=8.2 \pm$ $1.0 \mathrm{~s}^{-1}$ and $k_{\text {slow }}=0.38 \pm 0.05 \mathrm{~s}^{-1}$. The latter is identical, within error, with the measured steady-state $k_{\text {cat }}$ value. Quinonoid accumulation was not observed in the $\mathrm{L} \rightarrow \mathrm{D}$ direction with R219E or in either direction for WT, R219K, or R219A.

\section{DISCUSSION}

The observation of an arginine residue interacting with the pyridine nitrogen of PLP in the alanine racemase structure was a surprising result (7). A primary sequence alignment of 14 distinct isozymes of alanine racemase shows R219 to be strictly conserved (M. D. Toney, unpublished results). Residues interacting with the pyridine nitrogen in aminotransferase-like PLP-dependent enzymes of known structure $(9,11)$ and, by extrapolation based on sequence alignments
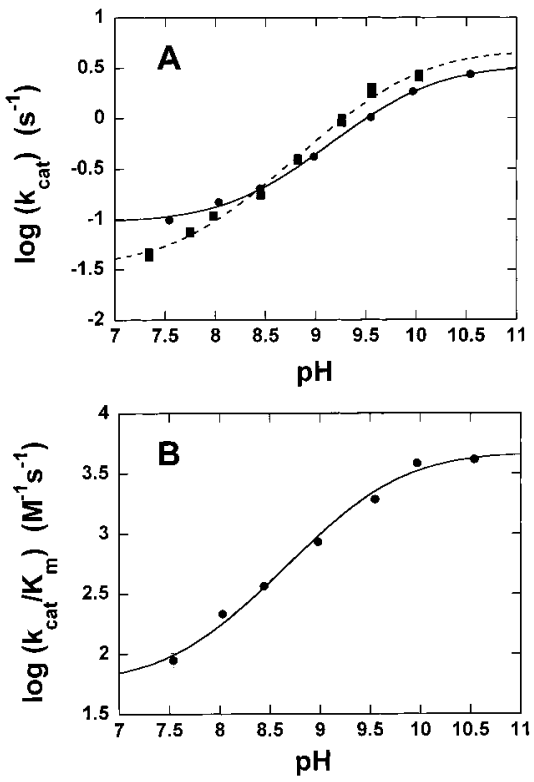

FiguRE 5: pH profiles for R219E: (A) $k_{\text {cat }}$, (B) $k_{\text {cat }} / K_{\mathrm{M}} \cdot(\bullet) \mathrm{D} \rightarrow$ $\mathrm{L}$ direction; $(\mathbf{\square}) \mathrm{L} \rightarrow \mathrm{D}$ direction. For $k_{\text {cat }}$, curves are the best fits to eq 6 for $\mathrm{D} \rightarrow \mathrm{L}$ (solid line) and for $\mathrm{L} \rightarrow \mathrm{D}$ (dashed line). For $k_{\text {cat }} /$ $K_{\mathrm{M}}$, the curve is the best fit to eq 7. $\mathrm{p} K_{\mathrm{a}}$ values are given in Table 3.

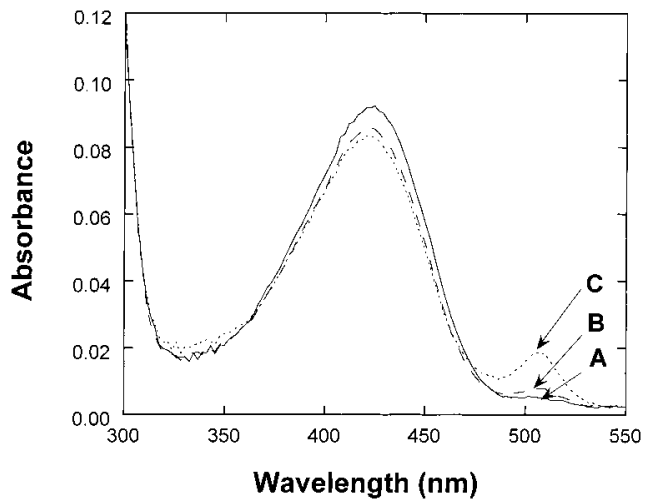

FIGURE 6: Absorbance spectra for the three species obtained from global analysis of the spectral changes in the pre-steady-state $\mathrm{D} \rightarrow$ $\mathrm{L}$ reaction between $\mathrm{R} 219 \mathrm{E}$ and alanine. A, initial species (solid line); $\mathrm{B}$, intermediate (long dashes); $\mathrm{C}$, final species (short dashes). The band at $\sim 510 \mathrm{~nm}$ is characteristic of a quinonoid intermediate.

(10), in a large number of other PLP-dependent enzymes are uniformly acidic. In the tryptophan synthetase family of PLP-dependent enzymes, the hydroxyl group of either a serine or threonine residue hydrogen-bonds to the pyridine nitrogen (12). The strict evolutionary conservation of residue type (i.e., acidic, neutral, or basic) within the enzyme families suggests that there are specific mechanistic reasons, particular to the reaction type being catalyzed, for these residues.

The mutation of R219 to lysine is functionally conservative. That is, the mutant enzyme retains approximately $25 \%$ of the WT enzyme activity in both the $\mathrm{D} \rightarrow \mathrm{L}$ and $\mathrm{L} \rightarrow \mathrm{D}$ directions, as judged by $k_{\text {cat }} / K_{\mathrm{M}}$ at $\mathrm{pH} 9.0$ (Table 1 ). On the other hand, the mutation of R219 to either a neutral (R219A) or an acidic (R219E) residue decreases $k_{\text {cat }} / K_{\mathrm{M}}$ by approximately 100- and 1000-fold, respectively. This demonstrates that alanine racemase requires a positively charged side chain at position 219 for optimal activity.

The structures of alanine racemase with acetate and L-alanine phosphonate bound $(7,22)$ show that $\mathrm{K} 39$, the 


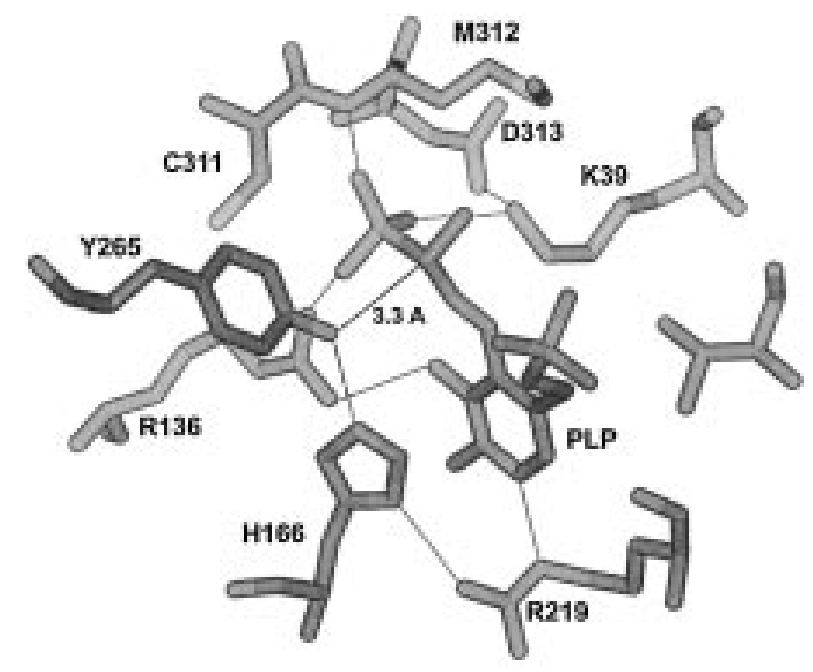

FIGURE 7: Active-site structure of alanine racemase with L-alanine phosphonate bound (22). The inhibitor forms an external aldimine. Thin lines represent hydrogen bonds. As indicated, the distance between $\mathrm{C} \alpha$ of the inhibitor and the Y265 hydroxyl group is 3.3 $\AA$ A. A hydrogen-bond network connects Y265 and R219 through H166.

lysine that forms a Schiff base with the coenzyme, is not structurally well positioned to be the general acid/base catalyst in a one-base racemization mechanism. Rather, the structurally more satisfying alternative is that of a two-base mechanism in which both K39 and Y265 function as general acid/base catalysts. The kinetic data of Sawada et al. (23) on the relative washout versus turnover rates for the D- and L-isomers also support a two-base mechanism for this enzyme. Mutation of Y265 to phenylalanine results in an enzyme with approximately 1000-fold reduced activity ( $\mathrm{T}$. Morollo and D. Ringe, personal communication). Thus, the existing structural and kinetic evidence supports a direct catalytic role for Y265 in a two-base racemization mechanism.

The active-site structure of L-alanine phosphonate bound to alanine racemase is shown in Figure 7. The inferred position of the $\alpha$-proton on the inhibitor places it within reach of the hydroxyl group of Y265. One clearly sees that R219 and Y265 are connected, via hydrogen bonding, through H166. This hydrogen-bond network could potentially lower, through transfer of positive charge from R219 to H166, the $\mathrm{p} K_{\mathrm{a}}$ of tyrosine to a near-neutral value by electrostatic stabilization of the phenolate anion. A low $\mathrm{p} K_{\mathrm{a}}$ would be required for Y265 to be an effective base catalyst under the near-neutral $\mathrm{pH}$ conditions found inside a bacterial cell. R219 thus selectively interacts with Y265 versus K39. This predicts that disruption of the H166-mediated hydrogen-bond network by mutation of R219 should selectively influence the ability of Y265 to act as a base catalyst in the $\mathrm{L} \rightarrow \mathrm{D}$ direction and as an acid catalyst in the $\mathrm{D} \rightarrow \mathrm{L}$ direction.

Kinetic Isotope Effects. Scheme 2 describes the origins of the primary and solvent deuterium KIEs for the reactions of both D- and L-alanine reported in Table 2 . In the $\mathrm{D} \rightarrow \mathrm{L}$ direction, $\mathrm{D}-\left[2-{ }^{2} \mathrm{H}\right]$ alanine causes proton transfer from $\mathrm{C} \alpha$ to $\mathrm{N} \epsilon$ of $\mathrm{K} 39$ to be subject to an isotope effect. This same proton transfer is affected by $\mathrm{D}_{2} \mathrm{O}$ solvent in the opposite, $\mathrm{L}$ $\rightarrow$ D direction since the protons on K39 (acting as a general acid) will exchange with solvent. The reciprocal of these effects also holds: $\mathrm{L}-\left[2-{ }^{2} \mathrm{H}\right]$ alanine in the $\mathrm{L} \rightarrow$ D direction causes proton transfer from $\mathrm{C} \alpha$ to $\mathrm{O} \xi$ of $\mathrm{Y} 265$ to be subject to an isotope effect, while $\mathrm{D}_{2} \mathrm{O}$ in the opposite, $\mathrm{D} \rightarrow \mathrm{L}$ direction has the same effect.

The KIEs presented in Table 2 support the above prediction that proton transfer between $\mathrm{C} \alpha$ and $\mathrm{O} \xi$ of Y265 should be selectively perturbed from the WT values by mutation of R219. The values of both ${ }^{\mathrm{D}} k_{\text {cat }}$ and ${ }^{\mathrm{D}} k_{\text {cat }} / K_{\mathrm{M}}$ for all three mutants in the $\mathrm{D} \rightarrow \mathrm{L}$ direction, in which $\mathrm{K} 39$ acts as the general base, are relatively unchanged from the WT values. The same KIE's for the opposite, $\mathrm{L} \rightarrow \mathrm{D}$ reaction, in which Y265 acts as the general base, are uniformly increased in the mutants. This provides strong, direct evidence that the relative energy barriers for proton transfers to and from $\mathrm{C} \alpha$ in the $\mathrm{D}$ versus $\mathrm{L}$ directions are asymmetrically perturbed by the mutations.

The solvent isotope effects are more complicated. Faraci and Walsh (5) provided evidence that Schiff base formation in either direction is partially rate-limiting in the $B$. stearothermophilus isozyme at $37^{\circ} \mathrm{C}$. The present experiments were conducted at $25{ }^{\circ} \mathrm{C}$, under which conditions Schiff base formation may well still be partially rate-limiting. Schiff base formation is expected to exhibit a small solvent KIE (24).

There is no strong, general trend toward increased solvent KIEs in the mutants in the data given in Table 2, except for ${ }^{\mathrm{DOD}} k_{\mathrm{cat}} / K_{\mathrm{M}}$ in the $\mathrm{D} \rightarrow \mathrm{L}$ direction. This trend is, like the primary effects in the $\mathrm{L} \rightarrow \mathrm{D}$ direction, consistent with selective debilitation of Y265 as a catalyst in the mutants. A similar increase in ${ }^{\mathrm{DOD}} k_{\text {cat }}$ in the $\mathrm{D} \rightarrow \mathrm{L}$ direction is expected but not observed in the data in Table 2. Qualitative differences in the origins of the KIEs were therefore sought.

The proton inventories shown in Figure 1 provide evidence for an altered origin of the solvent KIE in the $\mathrm{D} \rightarrow \mathrm{L}$ direction, in which Y265 would act as a general acid, but not in the L $\rightarrow$ D direction, in which Y265 would act as a general base. In the $\mathrm{L} \rightarrow \mathrm{D}$ direction, in which solvent labels K39, the proton inventories for both WT and R219E are linear, indicating a single proton in flight in the transition state. The $\mathrm{D} \rightarrow \mathrm{L}$ direction, in which solvent labels Y265, the mutant shows a clearly nonlinear proton inventory, unlike the WT, indicating a more complicated origin for the KIE with the involvement of multiple protons.

$p H$ Profiles. There is a general absence of information in the literature on the $\mathrm{pH}$ dependence of alanine racemase kinetic parameters. This motivated the determination of $\mathrm{pH}$ profiles for $k_{\text {cat }}$ and $k_{\text {cat }} / K_{\mathrm{M}}$ for the WT and mutant enzymes. Table 3 summarizes the $\mathrm{p} K_{\mathrm{a}}$ values measured for these enzymes.

The $\mathrm{pH}$ dependence of the kinetic parameters for the WT enzyme is likely to be a complex function of the $\mathrm{pH}$ dependence of multiple rate-determining steps, given the results of Faraci and Walsh (5). Titrations of enzyme-bound coenzyme absorbance over the $\mathrm{pH}$ range of 6-10.5 do not show any spectral changes (M. D. Toney, unpublished results), indicating that the Schiff base between K39 and PLP does not ionize, as is sometimes observed with PLPdependent enzymes. Thus, the lower $\mathrm{p} K_{\mathrm{a}}$ observed in $k_{\mathrm{cat}} l$ $K_{\mathrm{M}}$ does not originate in Schiff base ionization. One might speculate that the lower $\mathrm{p} K_{\mathrm{a}}(\sim 7.2)$ observed in both $k_{\text {cat }}$ and $k_{\text {cat }} / K_{\mathrm{M}}$ is largely associated with ionization of one of the two catalytic residues (K39 and Y265) in a two-base mechanism where one protonated and one unprotonated 
Scheme 2: Origins of the Primary and Solvent Isotope Effects ${ }^{a}$

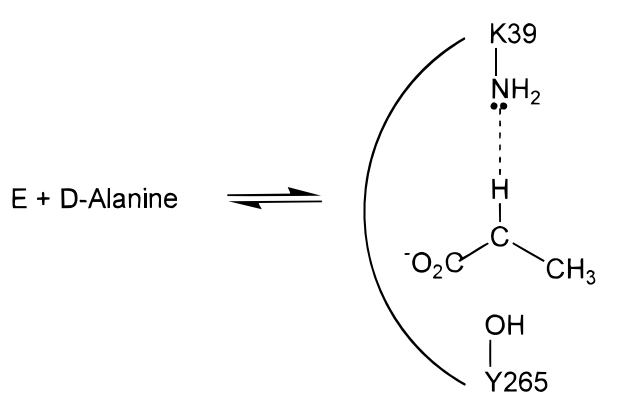

D-Alanine External Aldimine
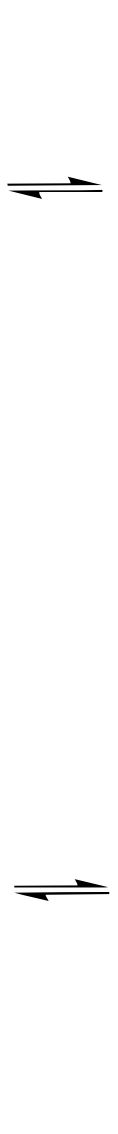

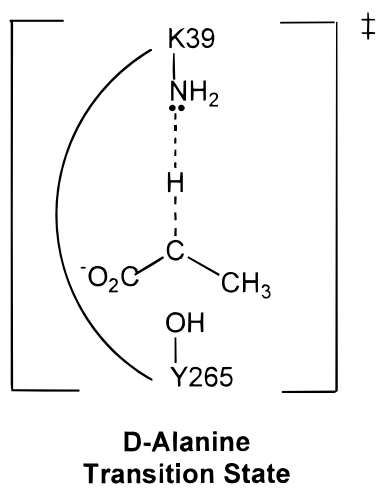

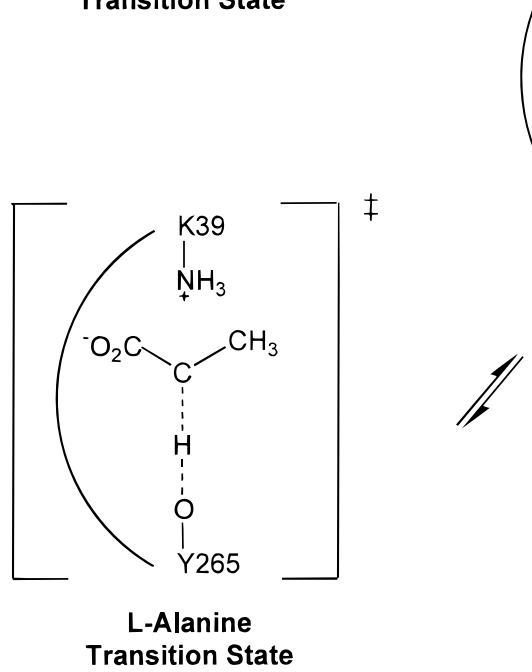
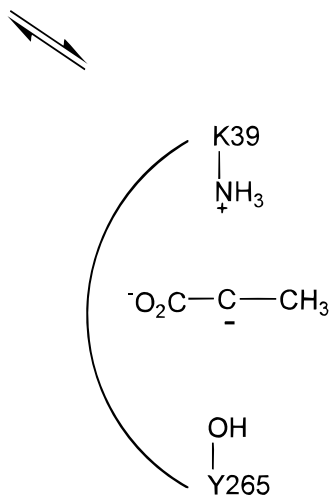

Quinonoid

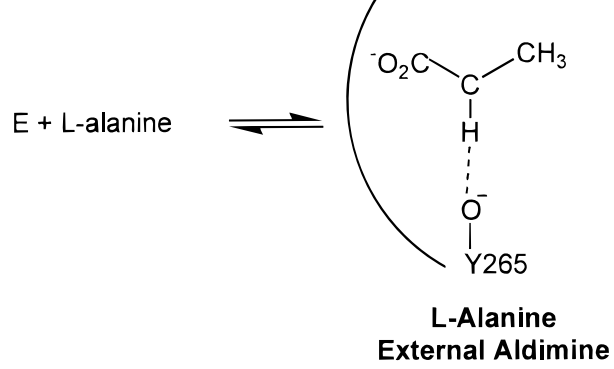

${ }^{a}$ Two proton transfer transition states are shown, one for each isomer. The proton in flight in the D-alanine transition state can be susbstituted with deuterium by: (1) $\mathrm{D}_{2} \mathrm{O}$ from the L-alanine direction since the protons on $\mathrm{K} 39$ are solvent exchangeable, or (2) labeling of C $\alpha$ on $\mathrm{D}-\mathrm{alanine}$. Likewise, the L-alanine transition state can be deuterium labeled either by $\mathrm{D}_{2} \mathrm{O}$ from the D-alanine direction or by labeling C $\alpha$ of $\mathrm{L}-\mathrm{alanine}$.

species is required. The higher $\mathrm{p} K_{\mathrm{a}}$ of 9.7 in $k_{\mathrm{cat}} / K_{\mathrm{M}}$ could, in principle, be associated with the $\alpha$-amino group of the free alanine $\left(\mathrm{p} K_{\mathrm{a}}=9.7\right.$ under the present experimental conditions), but the shift of this $\mathrm{p} K_{\mathrm{a}}$ to 10.5 in the R219A mutant and its absence (or shift out of the measurable $\mathrm{pH}$ range) in the $\mathrm{R} 219 \mathrm{E}$ mutant strongly weigh against this possibility. Rather, these data suggest that it is an activesite residue.

The conservative nature of the R219K mutation as judged by its high activity (Table 1) is also reflected in the $\mathrm{pH}$ dependence of the kinetic parameters. The only significant difference between WT and R219K is the appearance of an additional ionization in the $\mathrm{D} \rightarrow \mathrm{L}$ direction in $k_{\text {cat }}$ with a high $\mathrm{p} K_{\mathrm{a}}$ value (10.1).

The most notable $\mathrm{pH}$ results are with the $\mathrm{R} 219 \mathrm{~A}$ and R219E mutants. The ionization controlling $k_{\text {cat }}$ and the lower $\mathrm{p} K_{\mathrm{a}}$ in the bell-shaped curves for $k_{\text {cat }} / K_{\mathrm{M}}$ both increase from 7.1-7.4 (WT and R219K) to 9.5-10.4 (R219A and R219E). A simple interpretation of these observations is that the electrostatic perturbation of the Y265 pK $K_{\mathrm{a}}$ by R219 (or R219K), through the H166 hydrogen-bond network described above, is precluded in the mutants. The observed $\mathrm{p} K_{\mathrm{a}}$ values in R219A and R219E are indeed close to the solution value for tyrosine (10.1).

The $\mathrm{pH}$-independent value of $k_{\mathrm{cat}} / K_{\mathrm{M}}$ for R219A (17 800 $\mathrm{M}^{-1} \mathrm{~s}^{-1}$ ) is only 40-fold lower than that for WT. If one assumes that the effect of R219 on Y265 is a simple electrostatic one on its acidity, then this difference in $\mathrm{pH}$ - independent $k_{\text {cat }} / K_{\mathrm{M}}$ values suggests that the interaction between the R219 guanidino group and the pyridine nitrogen plays a minor role in the overall mechanism.

Quinonoid Intermediate in R219E. Pre-steady-state experiments with WT, R219K, and R219A show no indication of the presence of a quinonoid intermediate as judged by the lack of characteristic absorbance in the $450-550 \mathrm{~nm}$ region (25). R219E, on the other hand, shows the accumulation, in the $\mathrm{D} \rightarrow$ L direction only, of a band at $\sim 510 \mathrm{~nm}$ as the steadystate is approached. The approach to the steady-state is complex; two exponential processes are observed. The observed rate constants with saturating D-alanine are 8.2 and $0.38 \mathrm{~s}^{-1}$. The steady-state $k_{\text {cat }}$ value is $0.32 \mathrm{~s}^{-1}$ under these conditions. Thus, this intermediate is kinetically competent. The value of $0.38 \pm 0.05 \mathrm{~s}^{-1}$ for the slow phase is, within error, identical to the measured steady-state $k_{\text {cat }}$ value.

In the $\mathrm{D} \rightarrow \mathrm{L}$ direction, K39 would act as the base catalyst and Y265 as the acid catalyst in a two-base mechanism. If Y265 is selectively compromised as a catalyst in the mutant, then forward progress from the quinonoid via protonation by Y265 is expected to be slowed, with concomitant accumulation of this intermediate. The lack of accumulation to detectable levels of the quinonoid intermediate in the $\mathrm{L}$ $\rightarrow$ D direction is readily explained by the same argument, since slow deprotonation of the D external aldimine by Y265 would be followed by rapid reprotonation by the catalytically uncompromised K39. Thus, the appearance of the quinonoid in only the $\mathrm{D} \rightarrow \mathrm{L}$ direction is fully consistent with the 
arguments presented above supporting a direct role for Y265 as a general base catalyst in a two-base mechanism.

Jhee et al. (26) mutated the pyridine nitrogen-contacting serine in tryptophan synthetase (S377) to aspartate and found that a quinonoid intermediate accumulates. Grishin et al. (8) proposed that ornithine decarboxylase has an $\alpha / \beta$ barrel fold like alanine racemase, yet this enzyme appears to have an aspartate residue interacting with the PLP pyridine nitrogen. These observations combined with the present ones suggest that there are specific mechanistic imperatives for varying degrees of charge stabilization at the pyridine nitrogen, which have yet to be fully deciphered.

\section{REFERENCES}

1. Walsh, C. T. (1989) J. Biol. Chem. 264, 2393-2396.

2. Wood, W. A., and Gunsalus, I. C. (1951) J. Biol. Chem. 190, 403-416.

3. Duncan, K., Faraci, W. S., Matteson, D. S., and Walsh, C. T. (1989) Biochemistry 28, 3541-3549.

4. Thornberry, N. A., Bull, H. G., Taub, D., Wilson, K., GimenezGallego, G., Rosegay, A., Soderman, D. D., and Patchett, A. A. (1991) J. Biol. Chem. 266, 21657-21665.

5. Faraci, W. S., and Walsh, C. T. (1989) Biochemistry 28, 431437.

6. Copie, V., Faraci, W. S., Walsh, C. T., \& Griffin, R. G. (1988) Biochemistry 27, 4966-4970.

7. Shaw, J. P., Petsko, G. A., and Ringe, D. (1997) Biochemistry 36, 1329-1342.

8. Grishin, N. V., Phillips, M. A., and Goldsmith, E. J. (1995) Protein Sci. 4, 1291-1304.

9. Kamitori, S., Okamoto, A., Hirotsu, K., Higuchi, T., Kuramitsu, S., Kagamiyama, H., Matsuma, Y., and Katsube, Y. (1990) J. Biochem. (Tokyo) 180, 175-184.

10. Mehta, P. K., Hale, T. I., and Christen P. (1993) Eur. J. Biochem. 214, 549-561.
11. Toney, M. D., Hohenester, E., Cowan, S. W., and Jansonius, J. N. (1993) Science 261, 756-759.

12. Hyde, C. C., Ahmed, S. A., Padlan, E. A., Miles, E. W., and Davies, D. R. (1988) J. Biol. Chem. 263, 17857-17871.

13. Saito, H., and Miura, K. (1963) Biochim. Biophys. Acta 72, 619-629.

14. Tanizawa, K., Ohshima, A., Scheidegger, A., Inagaki, K., Tanaka, H., and Soda, K. (1988) Biochemistry 27, 1311-1316.

15. Inagaki, K., Tanizawa, K., Badet, B., Walsh, C. T., Tanaka, H., and Soda, K. (1986) Biochemistry 25, 3268-3274.

16. Ho, S. N., Hunt, H. D., Horton, R. M., Pullen, J. K., and Pease, L. R. (1989) Gene 77, 51-59.

17. Schowen, K. B., and Schowen, R. L. (1982) Methods Enzymol. $87 c, 551-606$.

18. Faraci, W. S., and Walsh, C. T. (1988) Biochemistry 27, 32673276.

19. Briggs, G. E., and Haldane, J. B. S. (1925) Biochem. J. 19, $338-339$.

20. Cleland, W. W. (1977) in Isotope Effects on Enzyme-Catalyzed Reaction; (Cleland, W. W., O'Leary, M. H., and Northrop, D. B., Eds.) pp 252-256, University Park Press, Baltimore, MD.

21. Quinn, D. M., and Sutton, L. D. (1991) in Enzyme Mechanism from Isotope Effects (Cook, P. F., Ed.) CRC Press, Boca Raton, FL.

22. Stamper, C. G. F., Morollo, A. A., and Ringe, D. (1998) Biochemistry 37, 10438-10445.

23. Sawada S., Tanaka, Y., Hayashi, S., Ryu, M., Hasegawa, T., Yamamoto, Y., Esaki, N., Soda, K., and Takahashi, S. (1994) Biosci. Biotechnol. Biochem. 58, 807-811.

24. Fischer, H., Decandis, F. X., Ogden, S. D., and Jencks, W. P. (1980) J. Am. Chem. Soc. 102, 1340-1347.

25. Metzler, C. M., Harris, A. G., and Metzler, D. E. (1988) Biochemistry 27, 4927-4933.

26. Jhee, K.-H., Yang, L.-H., Ahmed, S. A., McPhie, P., Rowlett, R., and Miles, E. W. (1998) J. Biol. Chem. 273, 11417-11422. BI982924T 